\title{
X-ray Tomography of the Antikythera Mechanism
}

\section{Andrew Ramsey ${ }^{1}$}

Nikon Metrology (was X-Tek Systems Ltd)

Unit 5, Tring Business Centre, Icknield Way, Tring, Hertfordshire, HP23 4JX, UK.

E-mail: andrew.ramseyenikonmetrology.com

\begin{abstract}
An "in-depth" explanation of how X-ray tomography revealed the secrets of the world's most ancient astronomical calculator, this talk will describe how X-Tek Systems Ltd, at the time a small UK-based X-ray company, developed a high resolution, high voltage X-ray source, took an 8-tonne cabinet to Greece and probed the secrets of surely the most fascinating artefact of ancient Greek culture. I will explain how X-ray computed tomography (CT) works, how we were able to see beneath the corrosion, count gear teeth and read inscriptions which had lain unread for 2000 years at the bottom of the Mediterranean Sea.
\end{abstract}

This paper will cover the following topics:

- The history of the Antikythera Mechanism

- Who were X-Tek and how did we get involved?

- Computed Tomography -What is it?

- Why is our CT different to medical CT?

- Microfocus X-ray sources - how do we magnify?

- High energy X-ray sources - how can we see through metal?

- Previous X-ray studies of the Mechanism

-What equipment did we use?

- How can we see buried features using CT?

- The findings... What is the Mechanism?

From Antikythera to the Square Kilometre Array: Lessons from the Ancients, Kerastari, Greece

12-15 June 2012

\footnotetext{
1 Speaker
} 


\section{Introduction}

From around $776 \mathrm{BC}$ to about 146BC the ancient Greeks dominated Mediterranean lands. They were masters in many of the arts and sciences: in architecture, sculpture, jewellery, sports, mathematics, astronomy and, as we now know, ancient Greek computing! If the last item seems surprising, then please read the rest of the remarkable story of the Antikythera Mechanism.

In 1900 sponge divers sheltered from a storm just off the island of Antikythera (which is the one "before Kythera"!) in the Mediterranean Sea between Crete and Greece. After the storm subsided they decided to dive and found an ancient shipwreck - a veritable treasure-ship. As well as dozens of marble and bronze statues, jewellery and other loot, they found a small wooden box. The box lay in a cupboard in the National Archaeological Museum in Athens and apart from a flurry of initial interest shortly after its discovery, wasn't studied in great detail until 1950 when an Englishman, Derek de Solla Price took an interest in it. The box had rapidly decayed - what he found were the remains of a bronze geared mechanism of remarkable workmanship. After many years of studying the numbers of teeth on the gear wheels Price formed the theory that the Antikythera Mechanism was an early astronomical computing machine. Was this the world's first computer? He wrote up his findings in a Scientific American article in $1959 .^{1}$
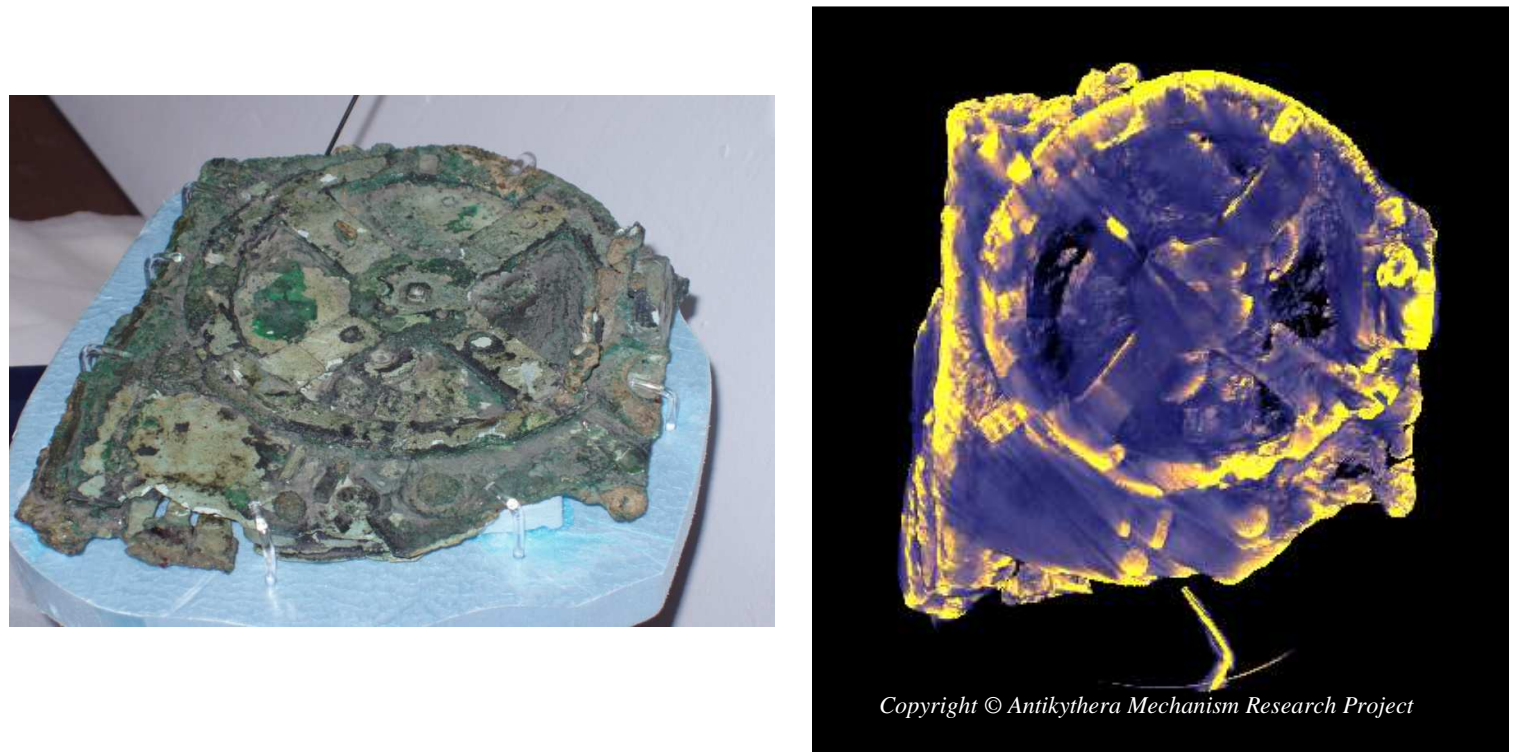

Figure 1: Left: A photograph of the largest fragment, Fragment A.

Right: $A 3 D$ rendering of the reconstructed $C T$ volume of Fragment $A$. 
The ship was Roman, but was full of Greek treasure. Was it on its way from Rhodes to Rome? In 79BC, the famous orator Marcus Tullius Cicero wrote in his Deorum, ${ }^{2}$ about "...the orrery recently constructed by our friend Posidonius, which at each revolution reproduces the motion of the sun, the moon and the five planets that take place in the heavens every day and night..." Now, Posidonius lived on the island of Rhodes, and studied under the school of the astronomer Hipparchus. Was the Antikythera Mechanism this "orrery" about which Posidonius wrote?

\section{The X-ray company}

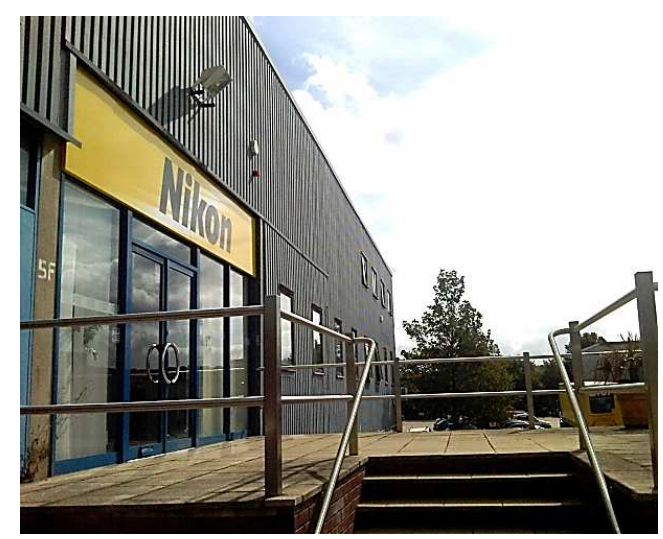

Fig. 2: Nikon Metrology's factory in Tring, Herts., UK

First of all, a little about the X-ray company known as "X-Tek Systems Ltd" who were contacted by London-based filmmaker Tony Freeth, the initiator of the Antikythera Mechanism Research Project, back in 2000. X-Tek Systems Ltd was a small family-owned company which manufactures industrial X-ray systems, both for radiography and $\mathrm{CT}$, in its factory in Tring, Hertfordshire, UK. It was started in 1986 by Roger Hadland. X-Tek Systems Ltd is now part of Nikon Metrology, wholly owned by the Japanese camera giant, Nikon Corporation. It builds and sells X-ray equipment all around the world. Its main customers are in the electronics industry, defence, automotive and aerospace industries, materials research, failure analysis and co-ordinate measurement.

Tony Freeth first approached X-Tek in 2000, aware of our high-resolution X-ray expertise. X-Tek's sales staff jumped at the chance to get involved in such a publicitygenerating project. However, Roger Hadland looked into what would be involved in inspecting such a large dense lump of corroded metal and decided he had better call Tony to break the bad news - our equipment was just not powerful enough. It would only take five minutes. One hour later, Roger was gripped by the fascinating story of the Mechanism and was convinced that we had to inspect it. He realised that an X-ray source powerful enough to inspect the Mechanism would have many other, revenue generating, applications. But by the time Tony got permission to inspect the Mechanism and Roger became involved, there were only six months left in which to do all the development work. Thus began the development of our high voltage X-ray source which would be very useful in inspecting aircraft turbine blades, the high resolution inspection and measurement of which was a large market. Because of this the CT system it would be used in would be known as the "BladeRunner". 
$\mathrm{X}$-Tek's industrial CT systems are similar in technology to medical body scanners, but use more powerful X-rays and much smaller X-ray sources to allow micron-sized features to be seen, as opposed to the typical millimetre-sized features in human bodies. More energetic X-rays can penetrate denser and thicker materials. When Roger called Tony our most powerful source was $225 \mathrm{kV}$, but Roger had ideas to create a much more penetrating $450 \mathrm{kV}$ source.

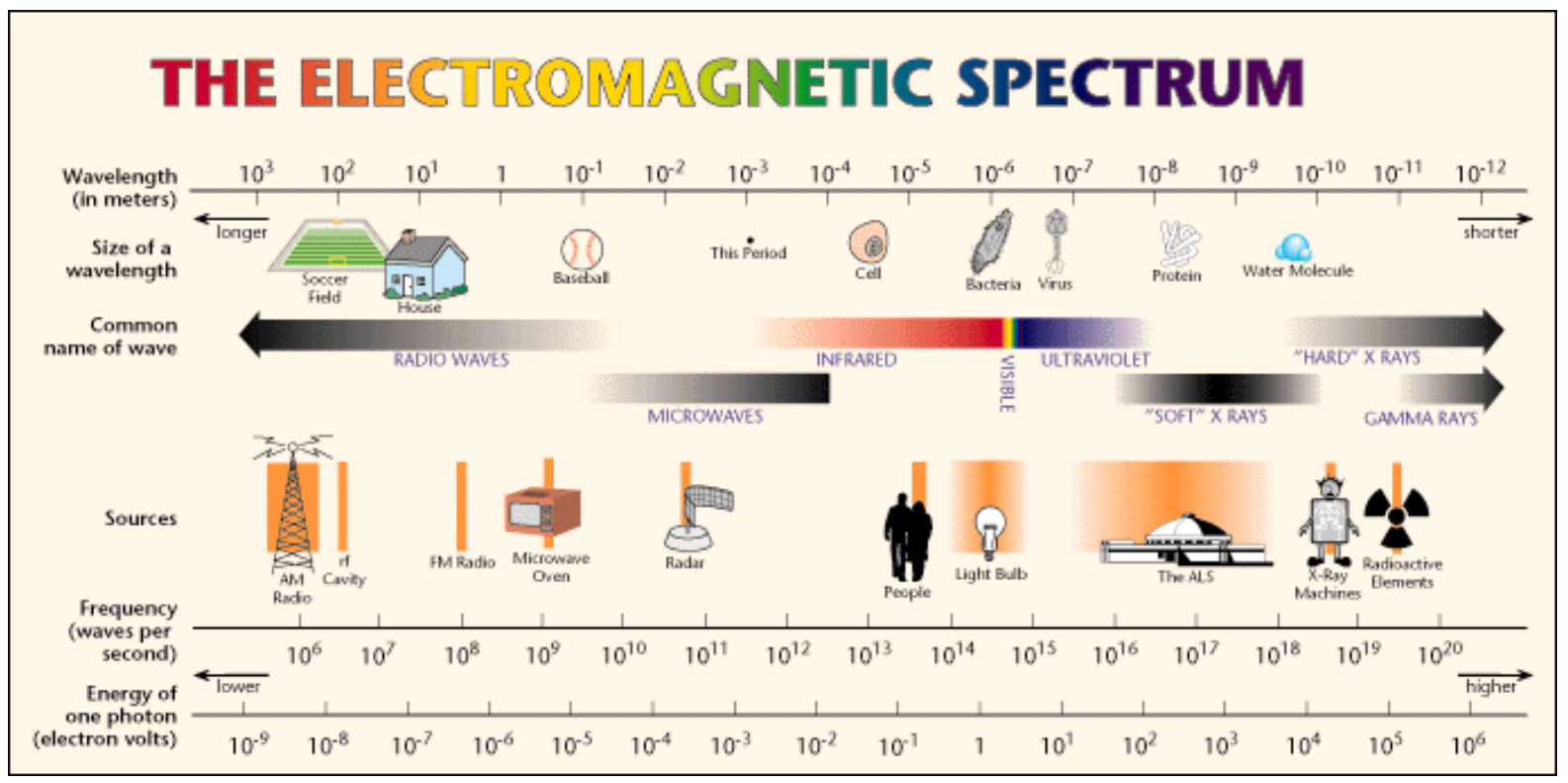

Figure 3: X-rays occupy a very small section of the total electromagnetic spectrum (image courtesy of NASA)

A note on X-rays: $\mathrm{X}$-rays are electromagnetic waves, like visible light, microwaves and radio waves. However X-rays are more energetic than visible light rays - so energetic in fact that they can penetrate right inside materials, even metals. However, passing through material reduces the intensity of the X-rays, and so can be used to produce a shadow image of the internal structure of the sample, with darker areas of the image in the places where the X-rays have travelled though more, or denser, material.

A quick description of the electromagnetic spectrum: At the low-energy end of the spectrum of electromagnetic waves we have radio waves, and then with increasing energy microwaves, and infra-red waves (which we feel as heat). Then comes the rainbow of visible light that we can see (blue light is more energetic than red light), followed by ultra-violet light and then X-rays. Finally, X-rays of very high energy (often produced by radioactive nuclei decaying) are called gamma rays. The energy is measured in electron-Volts - the energy an electron gains when it is accelerated across an electrical potential of one Volt. When electrons are accelerated through several thousand Volts (known as kilovolts or $\mathrm{kV}$ ) they travel at over half the speed of light. Their energy is measured in kilo-electron-Volts or keV. Different energy 
electromagnetic waves have different wavelengths (the higher the energy, the shorter the wavelength), but it is the energy of the waves which is more important in forming an image. X-Tek X-ray sources produce energies in the range $30-450 \mathrm{keV}$.

How do we generate $\mathbf{X}$-rays? Electrons are electrically charged particles found in all atoms. When the atoms are heated enough and a high enough electrical voltage is applied, the electrons can be sucked out of the atoms - this happens in the tungsten filament inside an X-ray source. The electrons are accelerated by the high voltage towards the metal target, which they hit at great speed. When the accelerated electrons interact with the electrons surrounding the atoms in the target, they are suddenly decelerated. Sudden deceleration of an electrical charge in an electrical field produces electromagnetic radiation. The more energy the electrons lose when they are decelerated, the higher the energy of the radiation they can emit.

If this radiation has enough energy then it is classed as X-rays. Over $99 \%$ of the electromagnetic radiation produced by the impact of the electrons on to the target is converted to heat (=random motion of the atoms within the target). Less than $1 \%$ has high enough energy to be called X-rays. If the electrons are focussed (using a magnetic lens) into a very small spot on the target, then the X-rays will be produced from a very small volume. Typically the electron spots in microfocus X-ray sources are less than $5 \mu \mathrm{m}(0.005 \mathrm{~mm})$ in size. The X-rays stream out of the target in straight lines. They then pass through the sample and hit the detector.

How do we generate images from X-rays? Just like light, $\mathrm{X}$-rays travel in straight lines. Unlike light, we cannot use a lens, so we have to use geometric magnification. This is similar to putting your hand between a candle and a wall. If you bring your hand closer to the candle the shadow on the wall gets larger. If the candle is small enough then the image remains sharp. Microfocal X-ray sources have an X-ray source which is only a small fraction of a millimetre in size. This means that you can place a small object very close to the X-ray source, a detector some distance away, and get a highly magnified, yet still very sharp image of the object on the detector. A conventional industrial or medical X-ray source would only produce a large image, but the details would be badly blurred. Medical X-ray sources produce radiation at a maximum energy of about $140 \mathrm{keV}$. This is enough to penetrate a human body but not enough to go through several centimetres of metal. To do this, higher energy X-rays are needed. XTek was the only company in the world which makes such a small but powerful X-ray source. The image of the X-ray absorption through an object is captured using a scintillator screen, which converts the X-ray energy into visible light energy, placed directly in front of an array of light-sensitive diodes, whose signals are captured by a computer. In the detector we used for the Mechanism there are 2000 by 2000 such diodes forming a 4-megapixel image, each pixel having a sensitivity of 16 bits - that's a dynamic range of 65535:1. Such a high dynamic range was needed because as such 
little flux can penetrate several centimetres of bronze the difference due to another millimetre of bronze is a very small difference compared to the total absorption.

The use of high-resolution, so called "microfocus", X-ray sources for industrial imaging is widespread. The electronics industry has used such devices for at least two decades, and in fact, exploiting this market area is what allowed X-Tek Systems to grow quickly in its early days. Any manufacturing process which needs to verify the correct assembly of a part; look for defects, such as cracks and porosity; any failure analysis laboratory where the cause of a failure is investigated; all of these may use X-ray equipment. Radiography, as simple X-ray imaging is called, has one big limitation though - all the features along the line of sight are superimposed on one another, and in the Antikythera Mechanism the many layers of gears prevented early researchers from counting the teeth on every gear. What was needed was a technique that could separate all these layers.

\section{Computed Tomography}

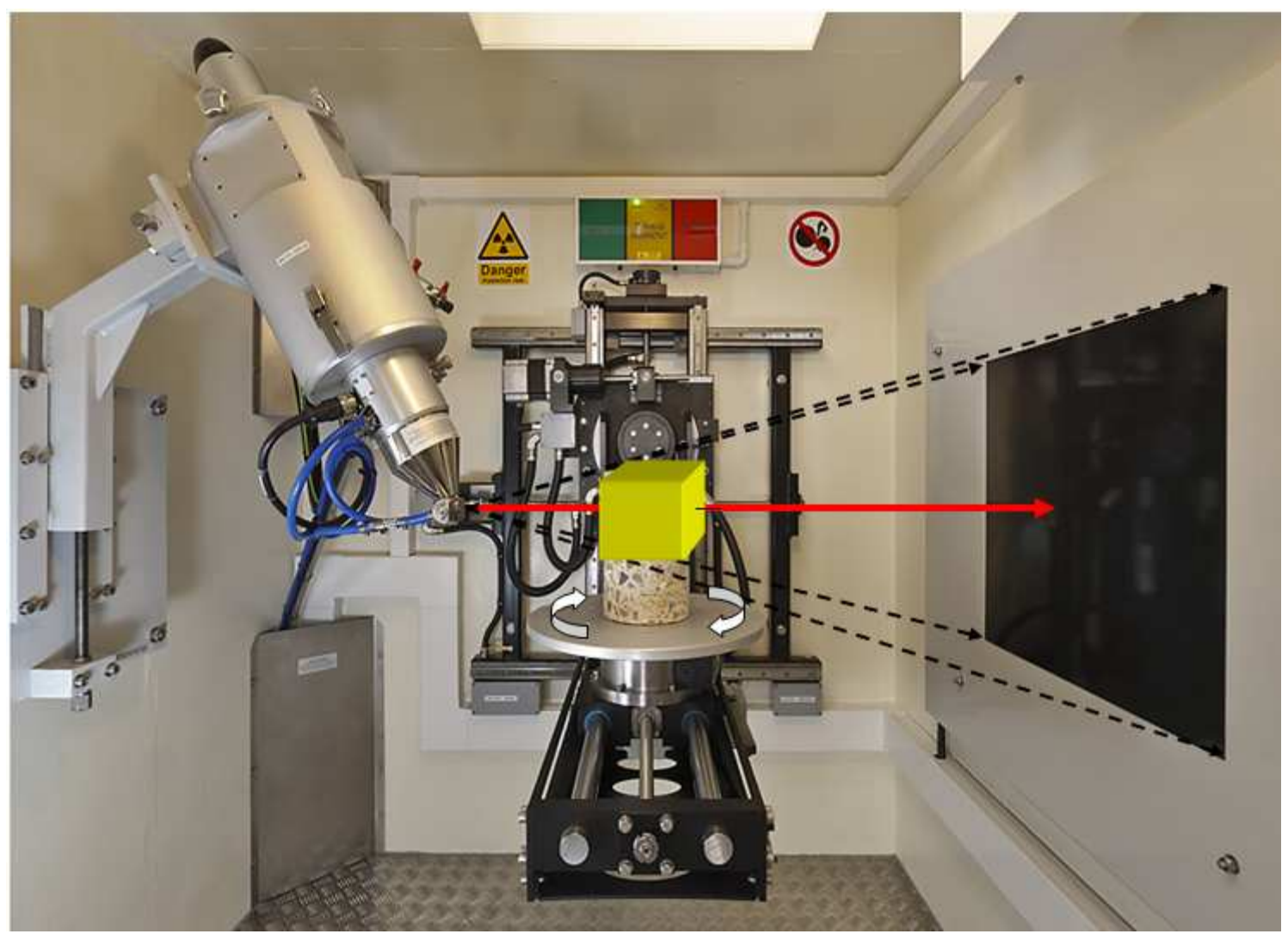

Figure 4: Inside one of X-Tek's X-ray CT systems showing the projection of an image of the sample onto the detector and the definition of a volume of interest to reconstruct. 
This technique is Computed Tomography, or CT, invented by Sir Godfrey Hounsfield in 1972 in the UK. Early CT systems were used for imaging the brains, and then the whole bodies of medical patients. Early work on industrial CT took place in the 1980s. The main difference between medical CT and industrial CT is that in the former the patient is kept still and the (very expensive) X-ray source and detector are swung around them on a precise gantry, whereas in the latter the X-ray source and detector are kept still and the sample is simply rotated on a turntable. Images need to be taken of the object from a large number of different angles during a single 360-degree rotation. The $\mathrm{X}$-rays thus must be able to pass through the object in all directions. This meant having a very high energy X-ray source in order to penetrate the Mechanism through its longer length.

Computer software is used to reconstruct the $3 \mathrm{D}$ volume from all these projection images. What is created is a 3D map of the linear X-ray attenuation within the sample. The sample is in effect digitised into billions of volume elements, or "voxels" (c.f. pixels = "picture elements"). The reconstruction algorithm worked by first filtering the images horizontally with a high-pass filter in order to remove the blurring caused by imaging the sample with X-rays. The projection image created can be thought of as a blurred version of the 3D sample, blurred along the direction of travel of the X-rays (generally horizontally if the sample is sitting on a turntable). Then each volume element, or voxel, is projected onto the relevant pixel in the filtered projection image and that pixel's value is added into the voxel. At the end of projecting each voxel onto this projection image, the next image (at the next angle) is considered until all of the projection images have been processed, at which point the reconstruction of the volume is complete. For good quality reconstructions, the object should not move by more than one voxel at the edge of the reconstruction volume. This means that for a volume $1000 \times 1000 \times 1000$, the best number of projections is pi $\mathrm{x}$ the number of voxels along one side $=3142$ projections.

\section{Previous inspections}

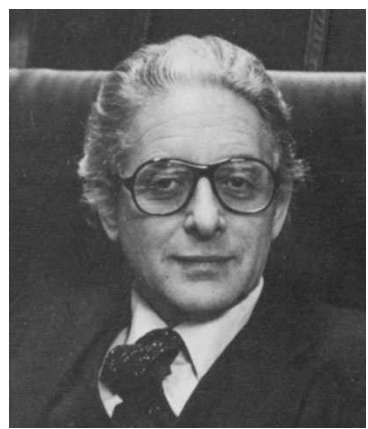

Fig. 5: Derek de Solla Price
This was not the first time the Antikythera Mechanism had been X-rayed. In fact the first X-ray images were taken in 1971 by De Solla Price. In 1990 Michael Wright of the Science Museum took some laminographic data. This involves moving the source and detector in synchronism while exposing the film. The layer of interest remains in the same place in the image while slices above and below move around and are therefore blurred. The technique is not as good as CT at separating the layers but does give a fair amount of three- dimensional information. However, for a number of reasons not connected to the technique, before 
2005 not a lot of the results from this work had yet been published. So it was in early 2005 that the Antikythera Mechanism Research Project, a collaboration of UK and Greek universities headed by Tony Freeth and Professor Mike Edmunds finally got permission to CT scan the fragments again. The transport of X-ray equipment to Greece was covered by the Leverhulme Trust, but X-Tek development time and staff time in Greece was given freely. Hewlett Packard in California were also involved using their Polynomial Texture Mapping (PTM) technique. A model of the Mechanism following the findings of Derek de Solla Price is in the National Archaeological Museum in Athens alongside the fragments of the Mechanism itself. Michael Wright had also made a model as a result of his X-ray laminography work. He and Alan Bromley had worked on the laminographic acquisition but Bromley had taken most of the data to Australia for several years and as a result Wright had yet to publish its main findings. The new Antikythera Mechanism Research Project involved Cardiff University, UK, Tony Freeth of Images First, The National and Kapodistrian University of Athens, the University of Thessaloniki, X-Tek Systems Ltd (now part of Nikon Metrology), based in Tring, and Hewlett Packard.

\section{Inspecting the Mechanism}

The largest fragment of the Mechanism is about $120 \mathrm{~mm}$ across. It is made of corroded bronze. We calculated that if it were the same density as bronze metal then $120 \mathrm{~mm}$ would attenuate a $225 \mathrm{kV}$ X-ray beam by 10 to the power 70 , and even a $450 \mathrm{kV}$ X-ray beam by 10 to the power 37 . So we were hoping for a lot of corrosion!

Many people commented that since X-Tek runs an X-ray inspection service in Tring, then why not simply ship the fragments of the Mechanism to Tring? But of course the Mechanism is far too fragile to be transported anywhere. So we had to ship our "BladeRunner" X-ray system to Greece - all eight tonnes of it! The lorry driver had arrived about two days before the system was ready. He stayed in Tring patiently waiting for our R\&D team to finish tweaking the system so that it would produce good quality CT data. Finally, at about 1am the system was loaded onto the lorry using our most capable fork-lift truck. Even this had to be counterbalanced with some of the lead we used for shielding our cabinets. 


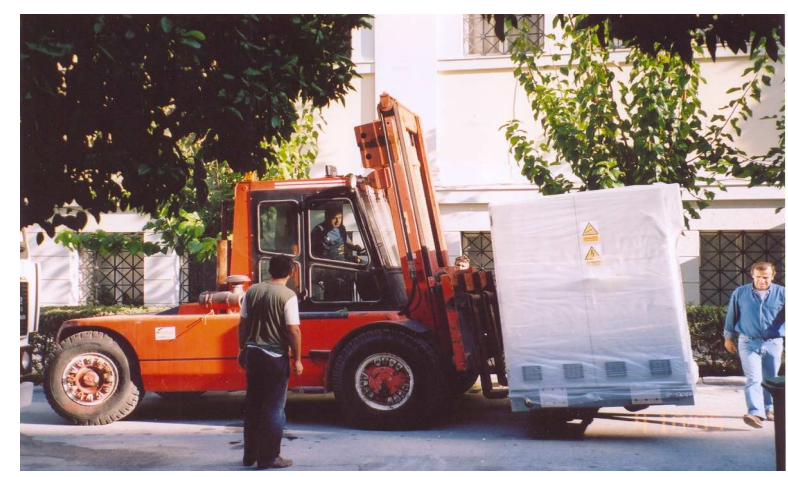

Fig. 6: Unloading the BladeRunner in Athens

Four days later, after $2500 \mathrm{~km}$ of travel, the BladeRunner arrived in Athens. It took almost a whole day to find a fork-lift truck large enough to lift the BladeRunner off the lorry. The one we used came from the docks and it delivered the system safely to the back door of the National Archaeological Museum, which since the museum is on a hill is the basement as far as the public are concerned. It took a lot of manhandling and pushing \& pulling with a mini-fork-lift truck to finally get the BladeRunner into the museum. The courtyard will never be the same again as it now contains the "X-Tek pothole".

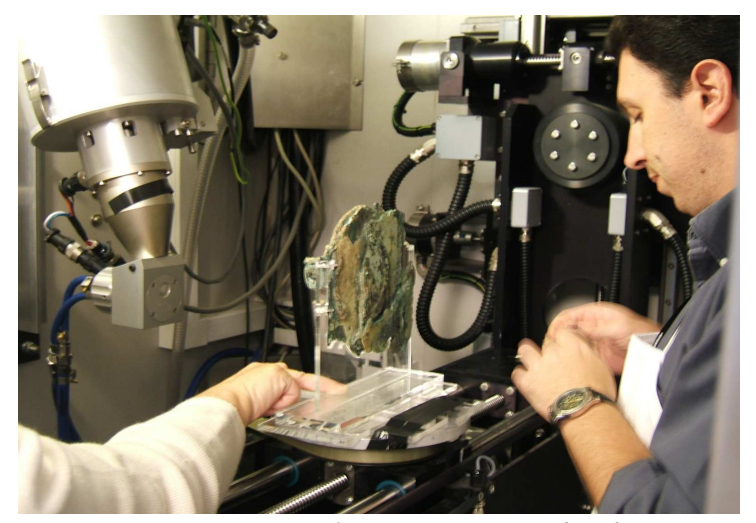

Fig. 7: Mounting fragment inside the CT scanner

Once the system was inside, the long process of unpacking, installation and commissioning began, all of this of course eating into our two and a half weeks allotted inspection time. Luckily everything went together well and the system worked when it was switched on. The fragments were handled only by the museum staff who had made some perspex holders to hold the fragments on the CT turntable. They had to be kept still during the $\mathrm{CT}$ rotation but the material holding them had to be fairly

transparent to X-rays. The X-ray source used to examine the Mechanism fragments was our new $450 \mathrm{kV}$ source. X-Tek's previous source was only $225 \mathrm{kV}$ which would not have been enough to penetrate the largest fragment. The $450 \mathrm{kV}$ source, which had been under recent rapid development by X-Tek's R\&D department is essentially two $225 \mathrm{kV}$ source barrels back to back - one negative, the other positive. The negative barrel has a filament at $-225 \mathrm{kV}$ and fires the electrons through the focusing lens which is at zero potential. In the $225 \mathrm{kV}$ source the electrons then hit a target also at zero volts, however in the positive barrel the potential of the target is raised to $+225 \mathrm{kV}$, so the electrons are accelerated from $-225 \mathrm{kV}$ to $+225 \mathrm{kV}$ and therefore hit the target with $450 \mathrm{kV}$ of kinetic energy. Because the target is not at ground it needs to be kept back from the front face of the source - in fact it is about $50 \mathrm{~mm}$ behind this face. This means that objects cannot be placed very close to the source to get very high magnification but then $450 \mathrm{kV}$ tends to be only used with objects which are fairly large and don't need very high 
magnification for CT. The focal spot in this combined source is about $50 \mu \mathrm{m}$ in size. The positive module could be taken off and replaced with a $3 \mu \mathrm{m} 225 \mathrm{kV}$ standard target which was useful for inspecting the smaller fragments.

The very small fragments were mounted in expanded polystyrene cylinders from a local arts shop. This meant that several small fragments could be scanned at once - useful as time was running short by the time we got to these. Over just over two weeks we collected over 600GB of CT data. Near the end we were buying the largest hard disks available from the local computer shop every day. Visitors to the museum at the time of the inspection were disappointed to find an empty display case. This included a longtime customer of X-Tek's who was in Athens at the time, totally unaware of our inspection work.

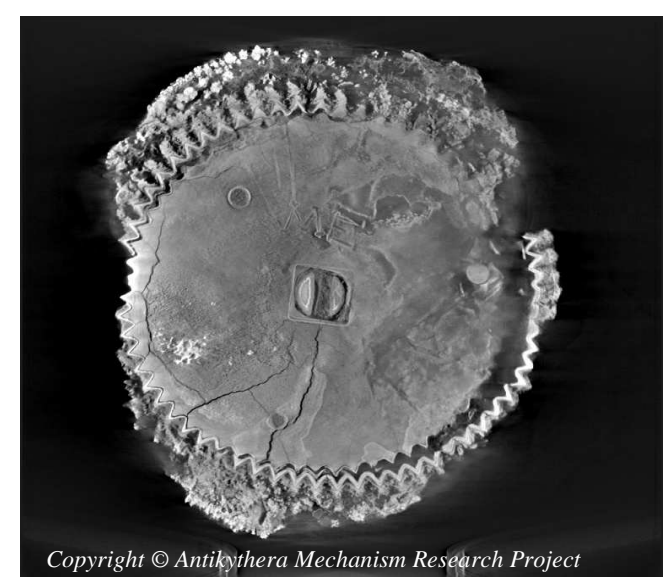

Fig. 8: Fragment D

Although it only took just over two weeks to collect and reconstruct the data, the analysis took a great deal longer. As well as allowing us to count accurately the number of teeth on the gear wheels the CT revealed large amount of buried inscriptions, as well as calendar scales and other engravings. The findings were written up and published in Nature $^{3}$ in December 2006 to coincide with a conference in Athens. At the public event in the evening of the conference there was standing room only for several hours. Over 30 gear wheels could be seen, each with hand-cut teeth. Engravings on some of the gears suggested a gear numbering system. There are two calendar dials - one showing the month names in a Corinthian dialect; the other is an eclipse prediction dial. Both dials are spiral with a slider on the pointer running in a groove rather like a gramophone needle. On some fragments were large amounts of text which appear to give instructions on how to use the Mechanism.

We are able to see the text in CT slices because the letters are either engraved or scratched onto the brass plates' surfaces. Thus in a CT slice the density within the slice drops in the engraving or scratch and therefore appears darker. There are also some plates which appear to contain "negative" writing from other plates which were squashed against them into which dirt or corrosion products seem to have collected. It takes a long time to decipher what is written on a given brass plate because the plates are not flat yet the CT slices are. Thus a painstaking process was involved, moving and rotating the CT slice about each letter's position and waiting for the slice image to redraw itself, repeated for each letter or small group of letters. 


\section{Conclusions}

The CT results showed that the Antikythera Mechanism was a complex lunar-solar calendar which modelled the position of the Sun and the Moon (and possibly Mercury and Venus) against the background stars. Using a set of eccentric gears and a pin and slot mechanism it modelled the elliptical nature of the Moon's orbit around the Earth. By recording solar and lunar eclipses on a 223-month spiral lunar calendar scale (the length of the Saros, or eclipse-repeat period $=18$ years, 11 days, 8 hours), the Mechanism was able to predict not only the months in which eclipses could occur, but also the time of day. It is not yet clear whether the records were historical (possibly Babylonian dating back to 600BC) or were predicted by the Mechanism itself. There was a small three-division dial showing the number of hours to add to the prediction, 8 , 16 or none. By showing that eclipses in successive cycles occur 8 hours later the Mechanism shows awareness of eclipses happening on the other side of the (round) world. Eratosthanes had already calculated the diameter of the Earth in about 250BC, and got a value of $13525 \mathrm{~km}$ (close to the true value of $12757 \mathrm{~km}$ ).

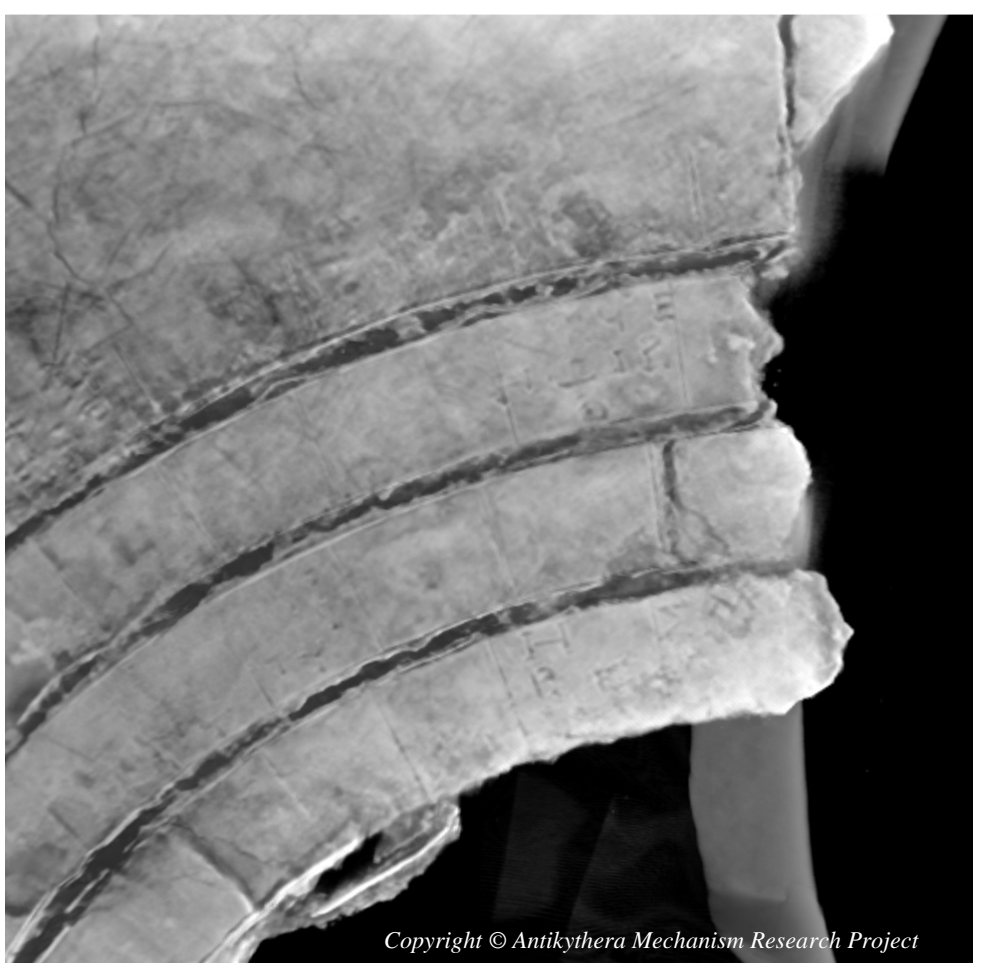

Fig. 9: An image of the Saros eclipse prediction dial Copyright $\odot$ Antikythera Mechanism Research Project

A slider on the dial pointers on the calendar displays rode in the spiral slot to indicate which part of the spiral to read from. On the Saros eclipse prediction dial this had to be reset every 18 years, 11 days. Each division represents one lunar month. A month is marked

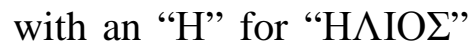
(= Sun) for a solar eclipse, or a " $\Sigma$ " for " $\Sigma \mathrm{E} \Lambda \mathrm{HNH}$ " (= Moon) for a lunar eclipse. The hour of the day is also marked. The day itself was either midmonth (full moon) for lunar eclipses or the end of the lunar month (new moon) for solar eclipses. The Moon's elliptical motion is driven by a pin on one gear and a slot in an eccentric gear above this. As the pin slides up \& down in the slot, the speed of the gear varies, just as the Moon's speed varies in its elliptical orbit. 
The month names on the lunar calendar are written in a Corinthian dialect, suggesting that the Mechanism was made in, or destined for use in, Corinth, or one of its colonies. One such colony is Syracuse, which is where the great inventor Archimedes lived in the fourth century BC. Perhaps he was the great mind behind this beautiful design?

\section{Acknowledgements:}

I would like to say a big thank you to all my colleagues at Nikon Metrology, especially: Martin Allen, David Bate, Bob Brailey, Alan Crawley, Roger Hadland, Ian Haig, Peter Hockley, Andrew Ray, Matt Williams. And I would also like to thank the Antikythera Mechanism Research Project team for inviting X-Tek to participate in this fascinating inspection. Finally I would like to thank Tasso Tzioumis for inviting me to this conference and for encouraging me to write this paper.

For more info see: http://www.xtekxray.com/antikythera.htm \& http://www.antikythera-mechanism.gr .

For more on Nikon Metrology see: www.nikonmetrology.com

\section{References:}

1. Derek de Solla Price, Scientific American, June 1959: “An Ancient Greek Computer" pp 60-67.

2. Marcus Tullius Cicero, De Natura Deorum (second book), 79BC: "Sphaera Posidonii”.

3. Tony Freeth, Mike Edmunds, Andrew Ramsey et al., Nature 444, 30 November 2006: "Decoding the ancient Greek astronomical calculator known as the Antikythera Mechanism”, pp 587-591. 